\title{
Physical activity and risk of peripheral arterial disease in the general population: Edinburgh Artery Study
}

\author{
E Housley, G C Leng, P T Donnan, F G R Fowkes
}

\begin{abstract}
Study objective-To determine associations between physical activity at age 35-45 years with peripheral arterial disease and cardiovascular risk factors at age 55-74 years.

Design-Cross sectional survey of the general population-Edinburgh Artery Study. The presence of peripheral arterial disease was determined using the WHO/Rose questionnaire on intermittent claudication, and the ankle brachial pressure index at rest and during reactive hyperaemia. Levels of physical activity undertaken at the time of the survey and at the times the subjects were aged 35-45 years were measured by self administered recall questionnaire.
\end{abstract}

Setting-City of Edinburgh, Scotland.

Participants-Altogether 1592 men and women aged 55 to 74 years, selected from the age-sex registers of 10 general practices spread geographically and socioeconomically throughout the city.

Main results-Participation in moderate or strenuous activity when aged $35-45$ years was reported by $66 \%$ of men and $40 \%$ of women. In men, but not in women, less peripheral arterial disease (measured by an increasing trend in the ankle brachial pressure index) was found with increasing amounts of exercise at age $35-45$ years $(p<0 \cdot 001)$. Higher levels of exercise at age $35-45$ years were associated with lower blood viscosity $(p<0.05)$ and plasma fibrinogen levels $(p<0.05)$ in men and women aged 55-74 years, and also with higher current alcohol intake $(p<0.001)$ and high density lipoprotein cholesterol concentrations $(\mathbf{p}<0.01)$ in women aged 55-74 years. After adjustment for age, sex, life-time smoking, social class, body mass index, and alcohol intake, the association between leisure activity aged 35-45 years and the ankle brachial pressure index aged 55-74 years remained highly significant in men who had at some time smoked $(p<0 \cdot 001)$ but not in men or women who had never smoked $(p>0 \cdot 05)$

Conclusion-The risk of peripheral arterial disease, particularly among male smokers, is inversely related to previous physical activity in early middle age, suggesting a protective effect of exercise.

7 Epidemiol Community Health 1993; 47: 475-480

The relationship between physical activity and ischaemic heart disease has been widely investigated, with most studies showing that exercise is associated with a lower rate of heart disease in later life. ${ }^{1}{ }^{\top}$ The protective effect of exercise was first identified by Morris et al who compared London bus drivers with bus conductors, and postmen with Post Office supervisors, and found lower mortality from heart disease in those doing more active work. ${ }^{1}$ Similar findings were reported by Khan, who compared letter carriers with mail clerks, ${ }^{2}$ and by Paffenbarger et al who compared San Francisco cargo handlers with sedentary longshoremen. ${ }^{3}$ With the general decline in physically strenuous occupations, more recent studies ${ }^{45}$ have concentrated on leisure time activity as a protective factor for ischaemic heart disease. In 1973, Morris et al investigated the reported leisure activities of London civil servants, and showed that the death rate from ischaemic heart disease over an eight year follow up period was appreciably reduced in those who had taken physical exercise. ${ }^{4}$ Leren et al made the interesting observation that the most favourable coronary risk profile occurred in men who did sedentary work but took vigorous leisure activity. ${ }^{5}$

The relationship between physical exercise and the risk of peripheral arterial disease has been investigated only in studies where the main concern was heart disease. In the Framingham Study, an association was found between low levels of physical activity and the development of intermittent claudication, but the association was not statistically significant after adjustment for age. ${ }^{8}$ In the Finnish cohort of the Seven Countries Study, however, "claudication was clearly associated with sedentary habits" at the 10 year follow up. ${ }^{9}$ The role of physical activity in protecting against peripheral arterial disease might be expected to be similar to that for ischaemic heart disease, but differences may arise because of variations in the relative importance of certain risk factors, particularly smoking, ${ }^{10}{ }^{11}$ and because the leg is directly involved in most forms of exercise.

The Edinburgh Artery Study ${ }^{12}$ is the first population survey in which physical activity has been measured in subjects examined for symptomatic and asymptomatic peripheral arterial disease. The objectives were to determine associations between physical activity at age $35-45$ years with peripheral arterial disease and cardiovascular risk factors at age $55-74$ years.

\section{Methods}

STUDY POPULATION

The Edinburgh Artery Study is a cross sectional survey of 1592 men and women aged 55 to 74 years, slected from the age-sex registers of 10 general practices with catchment populations spread geographically and socioeconomically 
throughout the city. The sample was selected at random within sex specific, five year age bands to produce equal numbers in each group. Subjects attended a university clinic to complete a questionnaire and to have a comprehensive medical examination. The response rate was $65 \%$, and follow up of a sample of non-responders did not show any substantial bias. Details of the study population, recruitment, and prevalence of peripheral arterial disease have been described previously. ${ }^{12}$ Ethics committe approval was given for this study, and informed consent was obtained from each patient.

\section{ASSESSMENT OF PHYSICAL ACTIVITY}

Levels of physical activity were determined using a self administered questionnaire (Appendix) adapted from the Welsh Heart Health Study questionnaire, ${ }^{13}$ previously validated against measures of cardiovascular fitness. ${ }^{14}$ Respondents were asked to assess the amount of activity undertaken during the last year, and when aged 35-45 years old; this last category was important in order to obtain a measure of previous physical activity which could be related to present disease status.

MEASUREMENT OF PERIPHERAL ARTERIAL DISEASE Symptomatic peripheral arterial disease was identified using the $\mathrm{WHO}$ /Rose questionnaire on intermittent claudication, ${ }^{15}$ and asymptomatic disease was detected by measuring the ankle brachial systolic pressure index at rest, and the change in ankle systolic pressure during reactive hyperaemia. Systolic and diastolic (phase V) blood pressures were taken in the right arm after 10 minutes rest in the supine position, using a random zero sphygmomanometer. Ankle systolic blood pressures were taken first in the right, then in the left leg using the random zero sphygmomanometer and a Doppler probe. Where possible, blood flow was detected at the ankle in the posterior tibial artery. In the reactive hyperaemia test, ankle systolic pressure was measured in the right and left legs 15 seconds after the release of a cuff occluding arterial flow above the knee for four minutes at approximately $50 \mathrm{mmHg}$ above systolic pressure. The timing was standardised using an electronic timer.

For descriptive purposes, the population was divided into four categories of peripheral arterial disease: (i) intermittent claudication (WHO questionnaire positive); (ii) major asymptomatic disease (ankle brachial pressure index $\leq 0.9$ and $>20 \%$ drop in ankle systolic presure after occlusion or ankle brachial pressure index $\leq 0.7$ or $>35 \%$ drop following occlusion); (iii) minor asymptomatic disease (ankle brachial pressure index $\leq 0.9$ or $>20 \%$ drop following occlusion); and (iv) normal values (none of the above). Since these categories have not been used in other studies the validities were unknown, but results of studies comparing the ankle brachial pressure index and the reactive hyperaemia response with angiography suggest that the classification had adequate face validity. ${ }^{16}$ The main analysis, however, concentrated on the ankle brachial pressure index because it was almost completely recorded and is a continuous measure, thus giving greater power to detect associations. In addition, the ankle brachial pressure index scems to be a good measure of peripheral arterial disease in population surveys, because decreasing levels have been shown to be associated both with disease severity detected on duplex scanning ${ }^{17}$ and with the prevalence of other markers of artherosclerosis such as angina and conventional cardiovascular risk factors. ${ }^{10}$

\section{STATISTICAL ANALYSIS}

Data were analysed on the Edinburgh University mainframe computer using the BMDP statistical package. ${ }^{18}$

Physical activity was classified into none, light, moderate, and strenuous for both leisure and occupational activity independently, according to the maximum amount of activity recorded in either summer or winter: no activity $=0$; maximum of light activity $=1$; maximum of moderate activity $=2$; maximum of strenuous activity $=3$. Current occupational activity was excluded from the analysis because many subjects were no longer in paid employment. Present activity was also excluded from the main analysis because symptomatic arterial disease inevitably produces low levels of activity, distorting any possible causal association between activity and the development of atherosclerosis.

Spearman rank correlation coefficients were calculated to show the relationship between physical activity at aged $35-45$ years and activity at the time of the survey, the ankle brachial pressure index, and risk factors for peripheral arterial disease. The $x^{2}$ test was used to examine the relationship between the four categories of peripheral arterial disease and the categories of leisure activity. A linear test for trend was performed for mean ankle brachial pressure index levels, and risk factors, across different categories of leisure activity. The distribution of the ankle brachial pressure index throughout the population was approximately normal .

The independent relationship between leisure activity at aged 35-45 years and disease was determined using multiple linear regression with the ankle brachial pressure index as the dependent variable. A significant leisure activity by sex and by smoking (ever $v$ never) interaction was found $(p=0.02)$, and therefore twelve dummy variables were created representing each of the leisure activity categories, relative to no activity in men and women, and ever and never smokers. Tests for interaction between additional risk factors were also carried out. The regression analysis adjusted for age, sex, social class, body mass index, alcohol, and smoking as measured by pack years (average number of packs of 20 cigarettes per day $\times$ number of years as a smoker). Square root transformations were used for smoking and alcohol consumption because of positive skewness.

\section{Results}

Forty eight per cent of men recalled taking part in some form of moderate leisure activity when aged $35-45$ years, and an additional $18 \%$ were undertaking strenuous leisure activity. Thirty seven per cent of women were taking some moderate physical exercise at this age, but only $3 \%$ were undertaking any strenuous activity. Eight per cent of 
Table I Leisure activity age 35-44 years in relation to severity of peripheral arterial disease at age 55-74 years

\begin{tabular}{llllc}
\hline & \multicolumn{5}{l}{ Subjects taking leisure activity (\%) } \\
\cline { 2 - 5 } & $\begin{array}{l}\text { Intermittent } \\
\text { claudication }\end{array}$ & $\begin{array}{l}\text { Major } \\
\text { asymptomatic } \\
\text { disease }(n=106)\end{array}$ & $\begin{array}{l}\text { Minor } \\
\text { asymptomatic } \\
\text { disease }(n=228)\end{array}$ & $\begin{array}{l}\text { No } \\
\text { disease } \\
(n=1071)\end{array}$ \\
\hline None & $12 \cdot 5$ & $10 \cdot 4$ & $10 \cdot 5$ & $8 \cdot 7$ \\
Light & $43 \cdot 1$ & $39 \cdot 6$ & $39 \cdot 5$ & $35 \cdot 4$ \\
Moderate & $38 \cdot 9$ & $41 \cdot 5$ & $39 \cdot 5$ & $44 \cdot 4$ \\
Strenuous & $5 \cdot 6$ & $8 \cdot 5$ & $10 \cdot 5$ & $11 \cdot 6$ \\
\hline
\end{tabular}

$\mathrm{x}^{2}=24 \cdot 55, \mathrm{p}=0 \cdot 02$

${ }^{\star}$ Grade of leisure activity is the maximum reported

114 subjects could not be classified for disease status

men and $12 \%$ of women were taking no leisure activity of note at this age. The amount of leisure activity undertaken when aged $35-45$ years showed good correlation with the amount of leisure activity undertaken at the time of the survey $(r=0.56, p<0 \cdot 001)$, although activity was slightly less at age 55 to 74 years.

Table I shows the proportion of subjects taking different levels of leisure activity when aged 35-45 years, for each category of arterial disease. There was a significant association between increasing disease and lower levels of exercise in the population as a whole $(p<0.05)$ and in men $(p<0.05)$, but not in women. An increasing trend in the proportions who undertook light or no activity was observed across the normal to the severe disease categories; a reverse trend of increasing strenuous exercise occurred from diseased categories to normal subjects. In men, but not in women, an increasing trend in ankle brachial pressure was found with greater amounts of exercise at age 35-45 years $(p<0.001)$, (figure).

Ankle brachial pressure index (ABPI) (mean $+2 S E M)$ in 809 men and 782 women aged 55-74 years in relation to leisure activity at age 35-45 years

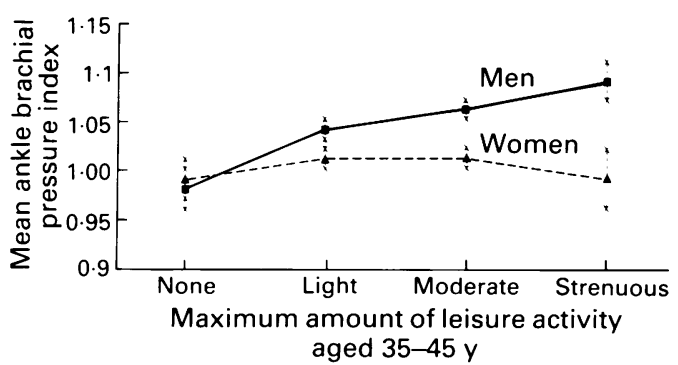

The amount of occupational activity undertaken at age 35-45 years was also significantly associated with the different categories of peripheral arterial disease present at the time of the survey $(\mathrm{p}<0.05)$ but, unlike leisure activity, no association was found with the ankle brachial pressure index in either men or women. There was a highly significant association between occupational activity and leisure activity at age $35-45$ years $(\mathrm{p}<0 \cdot 001)$.

The amount of leisure activity undertaken at age $35-45$ years was also significantly associated with several well established risk factors for peripheral arterial disease, measured at the time of the survey (table II). In women, higher levels of exercise at age 35-45 years were associated with higher current alcohol intake and high density lipoprotein cholesterol concentrations aged 55-74 years, and with lower levels of plasma fibrinogen and blood viscosity aged $55-74$ years. In men there was a similar association between previous high leisure activity and low blood vicosity, low plasma fibrinogen levels, and lower consumption of cigarettes at the time of the survey. Similar findings occurred on testing for linear trend. In both men and women, higher levels of leisure activity at age 35-45 years were associated with higher social class aged 55-74 years.

Table III shows the effect of correcting for age, sex, life-time smoking, social class, body mass index and alcohol intake, on the association between previous exercise and the ankle brachial pressure index separately in smokers and nonsmokers. In men who had ever smoked, there was a significant association between leisure activity at age 35-45 years and change in mean ankle brachial pressure index after adjustment for other risk factors, which increased with increasing amounts of exercise. In women, however, and in men who had never smoked, there was no significant association between leisure activity and the change in mean ankle brachial pressure index after correcting for the other risk factors.

\section{Discussion}

Physical activity is the process which promotes physical fitness, a biological marker of the body's ability to perform exercise. Studies examining both physical activity and fitness have shown them to be closely correlated, ${ }^{19}$ although fitness may be a more powerful predictor of disease, ${ }^{20}$ and more closely related to risk factors for coronary heart disease. ${ }^{19}$ Most population surveys have measured activity rather than fitness, primarily because it can be readily determined by questionnaire, and also because it has been shown to be protective against coronary heart disease. ${ }^{21} 22$ In addition, physical activity measured by recall questionnaires has shown good correlation with treadmill estimation of oxygen uptake, ${ }^{23}$ body composition, ${ }^{23}$ and forced expiratory volume, ${ }^{14}$ suggesting that it is a reasonably valid method.

Fewer women than men (41 $v 66 \%$ ) reported moderate or strenuous activity when aged 35-45 years. This is consistent with other findings, ${ }^{24}$ but may also have been exaggerated by the emphasis in the questionnaire on competitive sport, especially in the strenuous category, which may have been more relevant to men than women. In addition, some activities in the light category such as horse riding or sailing could, depending on their intensity and duration, actually be moderate or strenuous. Another potential problem was recall bias, which it was not feasible to assess. However, a recent study has shown the validity of recall of previous exercise over a 10 year period to be satisfactory, independent of recall interval and age. ${ }^{25}$

Table II Spearman rank correlation coefficients of leisure activity at age 35-45 years with risk factors for peripheral arterial disease at age 55-74 years

\begin{tabular}{|c|c|c|}
\hline \multirow[b]{2}{*}{ Risk factor } & \multicolumn{2}{|c|}{ Leisure activity at age $35-45$ years } \\
\hline & $\begin{array}{l}\text { Women } \\
(n=782)\end{array}$ & $\begin{array}{l}M_{(n=8} \\
(n=809)\end{array}$ \\
\hline $\begin{array}{l}\text { Body mass index } \\
\text { Smoking (pack years) } \\
\text { Alcohol intake } \\
\text { Social class } \\
\text { HDL cholesterol } \\
\text { Fibrinogen } \\
\text { Blood viscosity }\end{array}$ & $\begin{array}{r}-0.06 \dagger \\
-0.004 \\
0.15 \$ \\
-0.32 \$ \\
0.12 \ddagger \\
-0.08 \dagger \\
-0.15 \$\end{array}$ & $\begin{array}{l}-0.006 \\
-0.11 \ddagger \\
0.05 \\
-0.23 \$ \\
0.06 \\
-0.07 \dagger \\
-0.08 \dagger\end{array}$ \\
\hline
\end{tabular}

* Square root transformation

$t=p<0.05 ; \neq=p<0.01 ; \delta=p<0.001$ 
Table III Multiple regression of leisure activity at age 35-45 years on the ankle brachial pressure index (ABPI) at age 55-74 years by sex and cigarette smoking

\begin{tabular}{|c|c|c|c|c|}
\hline \multirow[b]{3}{*}{$\begin{array}{l}\text { Maximum leisure } \\
\text { activity } \\
\text { (relative to none) }\end{array}$} & \multicolumn{4}{|c|}{ Changes in mean (SEM) $A B P I^{\star}$} \\
\hline & \multicolumn{2}{|l|}{ Women } & \multicolumn{2}{|l|}{ Men } \\
\hline & $\begin{array}{l}\text { Ever } \\
\text { smoked } \\
(=386)\end{array}$ & $\begin{array}{l}\text { Never } \\
\text { smoked } \\
(n=382)\end{array}$ & $\begin{array}{l}\text { Ever } \\
\text { smoked } \\
(n=568)\end{array}$ & $\begin{array}{l}\text { Never } \\
\text { smoked } \\
(n=224)\end{array}$ \\
\hline Light & $\begin{array}{c}0.04 \\
(0.03)\end{array}$ & $\begin{array}{c}0.01 \\
(0.03)\end{array}$ & $\begin{array}{c}0.06 \dagger \\
(0.03)\end{array}$ & $\begin{array}{c}0.05 \\
(0.04)\end{array}$ \\
\hline Modeate & $\begin{array}{c}0.03 \\
(0.03)\end{array}$ & $\begin{array}{c}0.01 \\
(0.03)\end{array}$ & $\begin{array}{c}0.08 \ddagger \\
(0.03)\end{array}$ & $\begin{array}{c}0.03 \\
(0.04)\end{array}$ \\
\hline Strenuous & $\begin{array}{c}0.07 \\
(0.05)\end{array}$ & $\begin{array}{c}-0.07 \\
(0.06)\end{array}$ & $\begin{array}{l}0.10 \ddagger \\
(0.03)\end{array}$ & $\begin{array}{c}0.05 \\
(0.04)\end{array}$ \\
\hline
\end{tabular}

${ }^{\star}$ Adjusted for age, sex, life-time smoking, social class, body mass index, alcohol $t=p<0.05 ; \ddagger=p<0.001$
A highly significant linear increase in the mean ankle brachial pressure index was found with increasing leisure activity in men, but not in women. A similar dose-response relationship at all levels of exercise has been shown in physiological studies investigating the effects of exercise on other known risk factors, such as a high low density and low high density lipoprotein cholesterol concentration. ${ }^{26}$ Epidemiological studies have also shown reduced cardiovascular mortality at all levels of exercise, suggesting that even low levels are worthwhile, although there is little change in other risk factors. ${ }^{3} 27$

Multiple regression analysis showed that the increase in the ankle brachial pressure index with exercise was most noticeable in men who had at some time in their lives smoked. Similar multiple regression analyses for ischaemic heart disease $^{82628}$ and stroke $^{29}$ have shown physical activity to be an independent risk factor in men, but not women, ${ }^{30}$ although they have not identified that this occurred only in smokers, possibly because smoking is relatively less important in the aetiology of ischaemic heart disease than in peripheral arterial disease. ${ }^{31}$

The mechanism through which exercise protects against arterial disease has not been clearly established, but could operate via changes in blood lipid levels ${ }^{26}$ or rheological factors, ${ }^{32}$ both of which were shown to be associated with exercise in this study. Alternative mechanisms may include improvement of glucose intolerance and hyperinsulinaemia, ${ }^{33}$ reduction of blood pressure, ${ }^{34}$ plus the indirect benefit of maintaining body weight. Whatever the mechanism, increased levels of physical activity in earlier life seem to be beneficial in preventing cardiovascular disease. Our results suggest that physical activity is particularly important in men who smoke.

Funding was provided by the British Heart Foundation. The authors are grateful to the general practitioners who particiapted in this study, and to Elizabeth Cawood, Margaret Apps, Janet Dunbar, Eileen Kerracher, Anna Rattray, and Felicity Smith for collecting the data.

\section{Appendix \\ PHYSICAL ACTIVITY}

The following section gives examples of the sort of activities you might do or may have done regularly.

Light activity

Ballroom dancing

Bowling

Light do-it-yourself

Light gardening

Horse riding

Sailing

Walking (including to and from

work to shops etc)

Yoga

And other activities of similar intensity.

Please specify others you

have done.

Moderate activity
Badminton
Cricket
Cycling (include to and from
work, to shops etc)
Heavy do-it-yourself
Golf
Jogging
Swimming
Tennis

And other activities of similar intensity.

Please specify others you

have done.
Strenuous activity

Basketball

Competitive cycling

Competitive swimming

Competitive running

Field sports (such as rugby, soccer, hockey)

Training for strenuous sport Squash

And other activities of similar intensity.

Please specify others you

have done. 
(1) In a typical week during the past year, on how many occasions would you take part, for more than 20 minutes each time:

In light physical activity?

Insert "none" if appropriate

in summer ................... times

In moderate physical activity?

in winter.................... times

In strenuous physical activity?

in summer ................... times

in winter.................... times

in summer ................... times

in winter..................... times

(2) In a typical week, when you were 35-45 years old, on how many occasions would you take part, for more than 20 minutes each time:

In light physical activity?

In moderate physical activity?

Insert "none" if appropriate

in summer ................... times

in winter........................ times

In strenuous physical activity?

in summer $\ldots \ldots \ldots \ldots \ldots \ldots$ times
in winter ................... times

in summer .................. times

in winter................... times

Which of the following best describes your daily work or other daytime activity at the present time?

Please tick one box only.

I am usually sitting during the day and do not walk about much

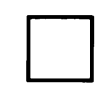

eg office workers, drivers

I stand or walk about quite a lot during the day but do not have to carry or lift things very often

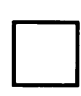

eg housewives, shop assistants

I usually lift or carry light loads and have to climb stairs and/or hills often.

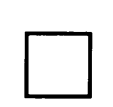

eg postmen, packers

I do heavy work and carry heavy loads

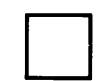

eg building, mining and agricultural workers

Which of the following best described your daily work or other daytime activity when you were $35-45$ years old? I usually sat during the day and did not walk about much eg office workers, drivers

I stood or walked about quite a lot during the day but did not have to carry or lift things very often

I usually lifted or carried light loads and had to climb stairs and/or hills often.

I did heavy work and carried heavy loads

eg housewives, shop assistants

eg postmen, packers

eg building, mining and agricultural workers

1 Morris JN, Heady JA, Raffle PAB, Roberts CG, Parks JW. Coronary heart disease and physical activity at work. Lancet 1953; ii: $1111-20$.

2 Kahn HA. The relationship of reported coronary disease mortality to physical activity at work. Am f Public Health 1963; 53: $1058-67$.

3 Paffenbarger RS, Laughlin ME, Gima AS, Black RA. Work activity of longshoremen as related to death from coronary heart disease and stroke. N Engl F Med 1970; 282:1109-14

4 Morris JN, Chave SPW, Adam C, Sirey C, Apstein L. Vigorous exercise in leisure-time and the Apstein L. coronary heart disease. Iancot 1973; i: 333-9.

5 Leren P, Askevold EM, Foss PO, it al. The Oslo Study. Cardiovascular disease in middle-aged and young Osio

6 Powell KE, Thompson PD, Casperen CJ, Kendrick JS. Physical activity and the incidence of coronary heart disease. Anysical activity and the incidence of coron

Annu Rev Public Health 1987; 8: 253-87.
7 Zimmet PZ, Collins VR, Dowse GK, et al. The relation of Zimmet PZ, Collins VR, Dowse GK, et al. The relation of
physical activity to cardiovascular disease risk factors in

Mauritians. Am f Lpidemiol 1991; 134: 862 -75.

Kannel $\mathrm{B}$, Sorle P. Some health benefits of physical activity. The Framingham Study. Arch Intern Med 1979;

9 Keys A, Aravanis C, Blackburn HW it al. Epidemiological studies related to coronary heart disease: Characteristics of men aged 40-59 in the seven countries. Acta Medica Scandinavia 1966; 460(suppl): 169-90.
10 Fowkes FGR, Housley E, Riemersma RA, et al. Smoking, lipids, glucose intolerance, and blood pressure as risk factors for peripheral atherosclerosis compared with ischaemic heart disease in Edinburgh Atery Study. Am $\mathcal{F}$ Epidemiol 1992; 135: 331-40.

11 Gordon T, Kannel WB. Predisposition to atherosclerosis in the head, heart and legs. FAM $A$ 1972; 221: 661-6.

12 Fowkes FGR, Housley E, Caswood EHH, MacIntyre CCA, Ruckley CB, Prescott RJ. The Edinburgh Artery Study. Prevalence of asymptomatic and symptomatic peripheral arterial disease in the general population. Int $\mathcal{F}$ Epidemiol 1991; 20: 284-392.

13 Welsh Heart Health Survey. Protocol and questionnaire. In: Heartbeat report No 2, Cardiff, Wales.

14 Welsh Heart Health Survey. Clincal Survey Results. In: Technical report No 20. Cardiff, Wales.

15 Rose GA. The diagnosis of ischaemic heart pain and intermittent claudication in field surveys. Bull WHO 1962;

16 Fowkes FGR. The measurement of atherosclerotic peripheral arterial disease in epidemiological surveys. Int $\mathcal{f}$ Epidemiol 1988; 17: 248 54

17 Fowkes FGR. Review of simple measuring techniques. In: Fowkes FGR, ed. Epidemiology of peripheral rascular disease. London: Springer-Verlag, 1991: 3-16.

18 Dixon WJ. BMDP statistical software mamal. Vol II. California: University of California Press, 1985. 
19 Lochen M-L, Rasmussen K. The Tromso study: physical fitness, self-reported physical activity and their relationship to other coronary risk factors. f Epidemiol Community. Health 10 other coronary

20 Sobolski J, Kornitizer M, De Backer G. Protection against ischaemic heart disease in the Belgian physical fitness study: ischaemic heart disease in the Belgian physical fitness study:
physical fitness rather than physical activity? $A m$ f Epidemiol physical fitness rath

21 Morris JN, Clayton DG, Everitt MG, Semmence AM, Burgess EH. Exercise in leisure-time: coronary attack and death rates. Br Heart f 1990; 63: 325-34.

22 Berlin JA, Colditz A. A meta-analysis of physical activity in the prevention of coronary heart disease. Am $\mathcal{F}$ Epidemiol 1990; 132: 612-27.

23 Jacobs DR, Ainsworth BE, Hartman TJ, Lean AS. A simultaneous evaluation of ten commonly used physical activity questionnaires. Med Sci Sport Exerc 1993; (in press).

24 Kuh DJL, Cooper C. Physical activity at 36 years: patterns and childhood predictors in a longitudinal study. 7 Epidemiol Community Health 1992; 46: 114-9.

25 Blair SN, Dowda M. Pate RR, et al. Reliability of long-term recall of participation in physical activity by middle-aged recall of participation in physical activity by middle-age
men and women. Am $\mathcal{f}$ Epidemiol 1991; 133: 266-75.

26 Haskell WL. Exercise-induced changes in plasma lipids and lipoproteins. Prev Med 1984; 13: 23-36.
27 Karvonen MJ. Physical activity in work and leisure time in relation to cardiovascular disease. Amm C/in Res 1982;14

28 Paffenbarger RS, Hyde RT. Exercise in the prevention of coronary heart disease. Prev Med 1984; 13: 3-22.

29 Lapidus L, Bengtsson C. Socioeconomic factors and Lapidus L, Bengtsson C. Socioeconomic factors and
physical activity in relation to cardiovascular disease and death $B r$ Heart 9 1986; 55:295.301.

30 Marti B, ot al. Relationship between leisure-time physical activity and risk factors for coronary heart disease in middle-aged Finnish women. Acta Medica Scandinazia 1987; 222: 223-30

31 Fowkes FGR. Epidemiology of atherosclerotic arterial disease in the lower limbs. Eur f V Vasi Surg 1988; 2: 283-291.

32 Ernst EEW, Matrai A. Intermittent claudication, exercise and blood rheology. Circulation 1987; 76: 1110-14.

33 Rauramaa R. Relationship of physical activity, glucose olerance, and weight management. Prev Med 1984; 13: $37-46$

34 Sallis JF, Haskell WL, Fortman SP, Wood PD, Vranizan KM. Moderate-intensity physical activity and cardiovascular risk factors. The Stanford five-city project. Prev Med 1986; 15: 561-8. 